\title{
Produção e qualidade de gérbera de corte submetidas a diferentes doses de potássio e épocas de colheita
}

\author{
Moisés A Muniz; José Geraldo Barbosa; Gabriel P Garde; Camila ML Alves \\ 1UFV-Depto. Fitotecnia,36570-000 Viçosa-MG; mmuniz76@gmail.com; jgeraldo@ufv.br; pradoufv@yahoo.com.br; cacalameiras@ \\ hotmail.com
}

\begin{abstract}
RESUMO
A cultura da gérbera se expande por todo o país. No entanto, poucas são as informações sobre suas exigências nutricionais. Para avaliar o efeito de doses de potássio e épocas de colheita na produção e qualidade de gérbera de corte ao longo do ano, foi conduzido um experimento em casa-de-vegetação com a cultivar Dinamyte em delineamento inteiramente casualizado, em esquema de parcelas subdivididas. As parcelas foram constituídas de cinco doses de potássio (0, 2, 4, 6 e $12 \mathrm{~g} /$ planta/ano) e as sub-parcelas de sete épocas de colheita de inflorescências $(12,15,19,23,25,28$ e 31 semanas após início dos tratamentos) e cinco repetições. Na colheita, foram avaliados o comprimento de haste, o diâmetro, a massa fresca e longevidade das inflorescências e teores de nutrientes no tecido foliar. Houve interação significativa entre doses de potássio e épocas de colheita para comprimento, massa fresca de haste e diâmetro de inflorescência, sendo que $6 \mathrm{~g}$ de potássio/planta/ano proporcionou diâmetro de inflorescência, comprimento e massa fresca de haste superiores nas avaliações feitas nas semanas 25 e 31 . A maior longevidade foi obtida com $7,8 \mathrm{~g}$ de potássio/planta/ano e a maior produção de hastes classificadas como extra foi obtida com 7,1 g de potássio/ planta/ano. A melhor qualidade da haste floral foi obtida com a dose de $6 \mathrm{~g} / \mathrm{planta} / \mathrm{ano}$, sendo que a qualidade das hastes florais variou ao longo do ano de cultivo sem influência das doses de potássio nas concentrações dos demais nutrientes.
\end{abstract}

Palavra-chave: Gerbera jamesonii, adubação, produtividade, longevidade, nutrição.

\begin{abstract}
Production and quality of gerbera under different potassium levels and harvesting times

The cultivation of gerbera is spread all over the country, but little information is available about nutritional requirements for this crop. In order to evaluate the effect of potassium and harvesting times for gerbera during the year, an experiment was carried out in a greenhouse with the cultivar Dinamyte in a completely-randomized split-plot design. The plots consisted of five doses of potassium $(0,2,4,6$ and $12 \mathrm{~g} /$ plant/year) and the sub-plots were seven harvesting times of inflorescences $(12,15,19,23,25,28$ and 31 weeks after the beginning of the treatment) with five replications. At harvest we evaluated length, diameter, fresh weight and longevity of the inflorescence and concentration of nutrients in leaf tissue. A significant interaction was observed between rates of potassium and harvest seasons for length of stem, fresh weight and diameter of inflorescence, and $6 \mathrm{~g}$ potassium/ plant/year provided the best inflorescence diameter, length and fresh weight of stem in weeks 25 and 31 . The highest longevity was obtained with $7.8 \mathrm{~g}$ of potassium/plant/year and highest production of stems classified as extra was obtained with $7.1 \mathrm{~g}$ potassium/plant/ year. The best quality of flower's stem was obtained with a dose of $6 \mathrm{~g} / \mathrm{plant} / \mathrm{year}$ and the quality of the flowers was variable during the year without influence of the rates of potassium on the concentration of the other nutrients.
\end{abstract}

Keywords: Gerbera jamesonii, fertilization, productivity, longevity, nutrition.

\section{(Recebido para publicação em 30 de outubro de 2012; aceito em 24 de outubro de 2013) (Received on October 30, 2012; accepted on October 24, 2013)}

\begin{abstract}
A cultura da gérbera se expande por todo o país, o que possibilita a geração de renda e emprego na região produtora. Para obtenção de lucro com a produção dessa cultura devem ser observados alguns fatores inerentes à qualidade da planta comercializada em vaso ou como flor de corte tais como a nutrição e adubação balanceada da cultura. Conhecer as necessidades nutricionais da cultura é preponderante para melhorar a eficiência da adubação, evitando-se o desperdício de adubo e a contaminação do ambiente. As recomendações sobre adubação para o
\end{abstract}

cultivo de gérbera em casa-de-vegetação servem apenas como referencial, tais como Mercurio (2002), pois há poucas informações. Em decorrência disso, as adubações utilizadas pelos produtores são derivadas das observações empíricas de técnicos de empresas.

Dentre os nutrientes, o potássio na planta tem como função regularizar o teor de carboidratos, óleos, gorduras e proteínas, estimular o enchimento de grãos, promover o armazenamento de açúcares e amido, aumentar a utilização da água e a resistência à seca, geada, pragas e doenças (Marschner, 1995; Grewal
\& Williams, 2002). Assim, o potássio é um elemento importante para a fisiologia da planta, pois é considerado grande construtor de qualidade, afetando significativamente a produção das plantas (Malavolta, 2006), conforme mostraram vários trabalhos. Rodrigues et al. (2008) constataram que o aumento das doses de potássio aumentou o diâmetro das inflorescências de crisântemo. Barbosa et al. (2007) observaram que o aumento da dose até $50,3 \mathrm{~g}$ de $\mathrm{K} / \mathrm{m}^{2} /$ ano propiciou maior qualidade de hastes de rosas.

Poucos são os relatos na literatura sobre a influência do potássio em plantas 
de gérbera como os de Dufault et al. (1990). Esses autores observaram que elevados níveis de $\mathrm{K}$ são necessários para aumentar a produção de flores comercializáveis, sugerindo dosagem de $220 \mathrm{~kg} \mathrm{ha}^{-1}$ de $\mathrm{N}$ e K para alcançar máxima produtividade, em plantas cultivadas em canteiro em casa-de-vegetação. Moharya (2004) observou maiores valores para comprimento de haste, diâmetro da flor e maior durabilidade pós-colheita nas doses mais altas de $\mathrm{P}$ e $\mathrm{K}$, avaliando doses de $\mathrm{P}(0 ; 7,5$; $\left.10 ; 12,5 \mathrm{mg} \mathrm{m}^{-2}\right)$ e de $\mathrm{K}(0 ; 10 ; 12,5 \mathrm{e}$ $15 \mathrm{mg} \mathrm{m}^{-2}$ ) na vida de vaso de gérbera conduzida sob casa-de-vegetação.

Considerando a escassa literatura sobre a adubação e nutrição de gérbera de corte em condições edafoclimáticas brasileiras, tanto em relação à exigência real da cultura como seu efeito na qualidade e produção, torna-se necessário o desenvolvimento de pesquisas visando obter essas informações. Assim, o objetivo foi avaliar o efeito de doses de potássio e épocas de colheita na produção e qualidade de hastes florais de gérbera de corte ao longo de um ano de cultivo.

\section{MATERIAL E METODOS}

$\mathrm{O}$ experimento foi conduzido em casa-de-vegetação em Viçosa-MG com plantas de gérbera de corte da cultivar Dinamyte, em canteiros na densidade de 9 plantas $/ \mathrm{m}^{2}$ (espaçamento de $30 \mathrm{~cm}$ entre linhas e $38 \mathrm{~cm}$ entre plantas).

O solo do canteiro (latossolo vermelho-amarelo, textura argilosa) (0-20 $\mathrm{cm})$ apresentou, antes do início dos tratamentos, as seguintes características químicas: $\mathrm{pH}\left(\mathrm{H}_{2} \mathrm{O}\right)=6,1 ; \mathrm{P}($ Mehlich-I $)$ e $\mathrm{K}=110,9$ e $109 \mathrm{mg} \mathrm{dm}^{-3}$; $\mathrm{Ca}, \mathrm{Mg}, \mathrm{Al}$, $\mathrm{H}+\mathrm{Al}, \mathrm{SB}, \mathrm{CTC}(\mathrm{t}), \mathrm{CTC}(\mathrm{T})=4,6 ; 0,6$; 0,$0 ; 1,2 ; 4,46 ; 5,48$ e $\left.9,94 \mathrm{cmol}_{\mathrm{c}} / \mathrm{dm}^{3}\right)$; $\mathrm{V}=55 \%$ e $\mathrm{m}=0 \%$.

$\mathrm{O}$ experimento foi instalado em delineamento casualizado, em esquema de parcelas subdivididas. As parcelas foram constituídas de cinco doses de potássio $(0,2,4,6$ e $12 \mathrm{~g} / \mathrm{planta} /$ ano $)$ e as subparcelas foram sete épocas de colheita das inflorescências (12, 15, 19, 23, 25, 28 e 31 semanas após início dos tratamentos) e cinco repetições. Cada parcela foi composta por 30 plantas. As doses de potássio foram aplicadas na forma de cloreto de potássio, sendo aplicadas as quantidades de $0 ; 0,038 ; 0,076 ; 0,115 \mathrm{e}$ $0,230 \mathrm{~g} / \mathrm{planta} / \mathrm{semana}$, totalizando-se $0 ; 2 ; 4 ; 6$ e $12 \mathrm{~g} / \mathrm{planta} /$ ano.

A irrigação foi realizada, por gotejamento, três vezes na semana em dias alternados, aplicando se volume de água até o solo atingir a capacidade de campo. Os tratos culturais foram realizados conforme a necessidade do cultivo.

Em cada época de colheita das inflorescências, foram avaliados: a) produção e classificação de hastes florais, quando a segunda ou terceira fileira de flores masculinas estivesse completamente aberta. Após a colheita, as inflorescências foram classificadas em extra e A1, conforme padrão IBRAFLOR. Para classe extra é necessário que a haste seja firme com comprimento superior a $45 \mathrm{~cm}$, inflorescências com aspecto sadio e coloração intensa e diâmetros superiores a $9,1 \mathrm{~cm}$. São classificadas como A1 hastes com pequena tortuosidade e comprimento mínimo de $30 \mathrm{~cm}$, inflorescências apresentando pequenos danos de pragas e doenças e diâmetro inferior a $9,1 \mathrm{~cm}$; b) comprimento de haste floral (medida da distância entre a base da haste até a inserção com a inflorescência); c) diâmetro da inflorescência (distância transversal entre as extremidades de lígulas opostas); d) massa fresca de haste floral: foi obtida a massa por ocasião da colheita (haste + inflorescência) após a padronização do seu comprimento em $40 \mathrm{~cm}$; e) massa seca de haste floral (após secagem em estufa a $70^{\circ} \mathrm{C}$ até massa constante).

Foi avaliada também a longevidade das inflorescências, sendo utilizadas hastes com a mesma classificação entre os tratamentos, cujo comprimento foi padronizado em $40 \mathrm{~cm}$. As hastes foram imersas em água, sendo trocada a água a cada 2 dias. A cada troca, foram cortados $2 \mathrm{~cm}$ da base da haste. O término da avaliação da longevidade ocorreu quando as inflorescências apresentavam uma das seguintes características: lígulas desprendiam da base da inflorescência; haste com curvamento superior a $90^{\circ}$ em relação a vertical; inflorescência com fechamento superior a $50 \%$ do seu diâmetro inicial.

Os dados foram submetidos à análise de variância e as médias comparadas pelo teste de Tukey. Para análise dos tratamentos quantitativos foi usada análise de regressão, cujos modelos foram escolhidos com base na significância

Tabela 1. Comprimento médio de haste floral e diâmetro da inflorescência de gérbera em função de doses de potássio e de colheitas em diferentes semanas após início dos tratamentos (average length of floral stems and diameter of inflorescences of gerbera depending on rates of potassium, harvested in different weeks after aplication of treatments). Viçosa, UFV, 2010-2011.

\begin{tabular}{lccccccc}
\hline $\begin{array}{l}\text { Dose de K } \\
\text { (g/planta/ }\end{array}$ & \multicolumn{6}{c}{ Comprimento de haste floral (cm) } \\
\cline { 2 - 7 } ano) & $\mathbf{1 2}$ & $\mathbf{1 5}$ & $\mathbf{1 9}$ & $\mathbf{2 3}$ & $\mathbf{2 5}$ & $\mathbf{2 8}$ & $\mathbf{3 1}$ \\
\hline & $52,8 \mathrm{Aab}$ & $50,5 \mathrm{Bb}$ & $62,5 \mathrm{Aa}$ & $51,3 \mathrm{Bab}$ & $51,3 \mathrm{Bab}$ & $57,5 \mathrm{Bab}$ & $50,0 \mathrm{BCb}$ \\
2 & $55,0 \mathrm{Aa}$ & $60,6 \mathrm{Aa}$ & $53,0 \mathrm{Ba}$ & $51,6 \mathrm{Ba}$ & $51,0 \mathrm{Ba}$ & $62,3 \mathrm{ABa}$ & $54,1 \mathrm{Ba}$ \\
4 & $44,8 \mathrm{Ab}$ & $51,0 \mathrm{Bab}$ & $58,0 \mathrm{ABab} 52,2 \mathrm{Bab}$ & $52,0 \mathrm{Bab}$ & $63,3 \mathrm{ABa}$ & $53,3 \mathrm{Bab}$ \\
6 & $53,0 \mathrm{Aa}$ & $60,25 \mathrm{Aa}$ & $64,3 \mathrm{Aa}$ & $62,7 \mathrm{Aa}$ & $61,0 \mathrm{Aa}$ & $65,3 \mathrm{Aa}$ & $66,6 \mathrm{Aa}$ \\
12 & $49,8 \mathrm{Aa}$ & $55,7 \mathrm{ABa} 54,0 \mathrm{Ba}$ & $49,6 \mathrm{Ba}$ & $53,1 \mathrm{Ba}$ & $57,1 \mathrm{Ba}$ & $45,6 \mathrm{Ca}$ \\
\hline \multicolumn{7}{c}{ Diâmetro da inflorescência (cm) } \\
\hline 0 & $9,6 \mathrm{Bab}$ & $9,1 \mathrm{Bb}$ & $10,6 \mathrm{Aa}$ & $9,6 \mathrm{ABab}$ & $9,8 \mathrm{Bab}$ & $10,0 \mathrm{Aab}$ & $9,5 \mathrm{Cab}$ \\
2 & $9,8 \mathrm{Ba}$ & $10,1 \mathrm{ABa}$ & $9,8 \mathrm{Ba}$ & $9,0 \mathrm{Ba}$ & $9,7 \mathrm{Ba}$ & $10,3 \mathrm{Aa}$ & $10,6 \mathrm{ABa}$ \\
4 & $10,0 \mathrm{Ba}$ & $9,5 \mathrm{Ba}$ & $10,1 \mathrm{ABa}$ & $10,1 \mathrm{Aa}$ & $10,0 \mathrm{Ba}$ & $10,8 \mathrm{Aa}$ & $10,7 \mathrm{Aa}$ \\
6 & $10,0 \mathrm{Ba}$ & $10,6 \mathrm{Aa}$ & $10,2 \mathrm{ABa}$ & $9,8 \mathrm{Ba}$ & $11,3 \mathrm{Aa}$ & $10,8 \mathrm{Aa}$ & $11,3 \mathrm{Aa}$ \\
12 & $11,2 \mathrm{Aa}$ & $9,3 \mathrm{Ba}$ & $10,6 \mathrm{Aa}$ & $9,1 \mathrm{ABa}$ & $10,3 \mathrm{Ba}$ & $10,8 \mathrm{Aa}$ & $9,6 \mathrm{BCa}$ \\
\hline
\end{tabular}

Médias seguidas da mesma letra maiúscula na coluna e minúscula na linha não diferem entre si pelo teste de Tukey ao nível de 5\% de probabilidade (means followed by same uppercase letter in column and lowercase letter in line do not differ by Tukey test at 5\% probability). 
dos coeficientes, mediante aplicação do teste " $t$ ", a $5 \%$ de probabilidade e dos coeficientes de determinação.

\section{RESULTADOS E DISCUSSÃO}

Houve interação significativa entre as doses de potássio e época de colheita para o comprimento, o diâmetro (Tabela 1), a massa fresca e seca das hastes florais (Tabela 2 ).

O comprimento da haste floral e o diâmetro da gérbera superiores foram obtidos com $6 \mathrm{~g} /$ planta/ano de potássio nas semanas 23, 25, 28 e 31 e nas sema- nas 15 e 25, respectivamente (Figura 1). A mesma dose proporcionou também a maior massa fresca de haste nas semanas 25 e 31 (Tabela 2). Esse período é concordante com o final do estádio vegetativo da gérbera (cinco semanas após o plantio), quando inicia a emissão de hastes florais. Considerando que a gérbera é comercializada em maços de 20 hastes, independente da massa e dependente do comprimento e diâmetro, pode-se dizer que o potássio apresentou-se como um aliado para os produtores, especialmente nos períodos avaliados. Resultados contrários foram obtidos por

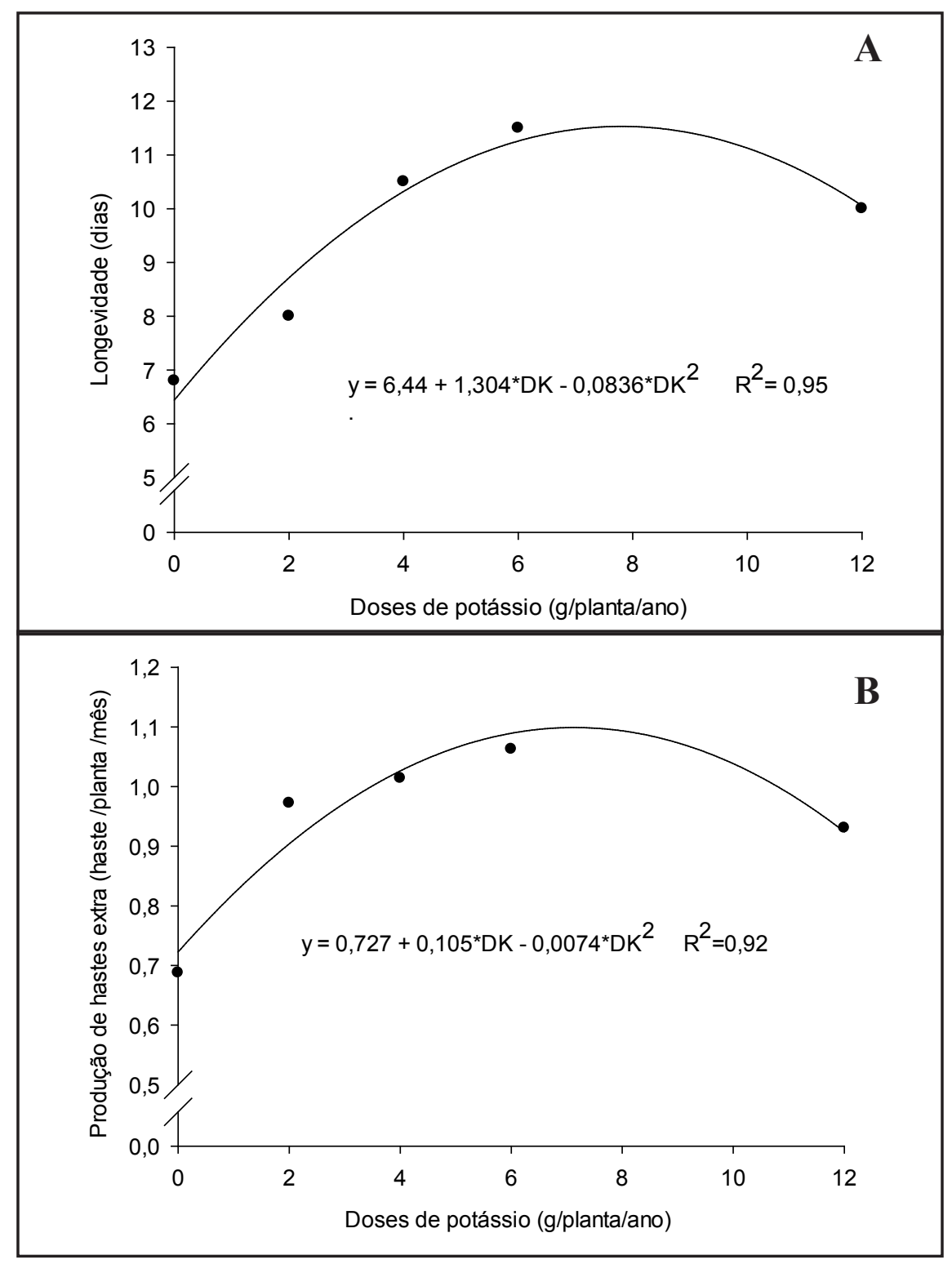

Figura 1. Longevidade de inflorescência (A) e produção de hastes do tipo extra (B) em plantas de gérbera em função de doses de potássio (longevity of inflorescence and production of extra-type stems in gerbera plants depending on doses of potassium). Viçosa, UFV, 2010-2011.
Ludwig et al. (2010) que não observaram efeito do aumento da concentração de potássio na solução de fertirrigação para diâmetro de inflorescência em cultivares de gérbera de vaso, assim como Rodrigues et al. (2008), que não observaram diferenças no comprimento de haste, diâmetro, massa fresca em espécie similar (crisântemo) cultivada em vaso com aplicação via fertirrigação de doses até $400 \mathrm{mg} \mathrm{L}^{-1}$ de $\mathrm{K}$.

O potássio atua como ativador de enzimas fotossintéticas, respiração, síntese protéica e na abertura dos estômatos, sendo que sua deficiência acarreta menor translocação de fotoassimilados para as partes de interesse comercial (Taiz \& Zeiger, 2008). Desta forma, os resultados mostram que a dose de $6 \mathrm{~g} / \mathrm{planta} /$ ano foi adequada no sentido de suprir potássio na quantidade ideal para o crescimento e desenvolvimento das plantas, pois proporcionou maior comprimento de haste e maior diâmetro de inflorescências. A variação nos parâmetros avaliados, em função das épocas de colheita, pode ter ocorrido em resposta às variáveis climáticas, especialmente temperatura, uma vez que na semana 12 após início dos tratamentos (agosto), a média foi de $17,5^{\circ} \mathrm{C}$, enquanto nas semanas 23 e 31 as médias foram 23,2 e $27,5^{\circ} \mathrm{C}$ respectivamente, que são menores que a faixa ideal (22 a $26^{\circ} \mathrm{C}$ ) de Singh (2006). Aliado a isso, o maior volume de massa fresca com o aumento do potássio aplicado, pode ser explicado pelo aumento da concentração de $\mathrm{K}$ no citoplasma das células elevar o potencial osmótico do vacúolo e, como consequência, ocorrer maior absorção de água pela célula, acarretando em maior massa fresca do tecido (Taiz \& Zeiger (2008).

A longevidade das inflorescências de gérbera também foi afetada pelas doses de potássio, sendo a máxima longevidade obtida com 7,8 dias de potássio/planta/ano, a qual possibilitou vida pós-colheita de 9,98 dias (Figura 1A). Esse resultado é concordante com o de Barbosa (2009) que, estudando relações $\mathrm{N}: \mathrm{K}$ em crisântemo de corte, em sistema hidropônico, constatou que maior longevidade de inflorescência foi obtida na relação 1:4, ou seja, aumentou com o potássio aplicado. Entretanto, no 
Tabela 2. Massa fresca e seca de haste floral ( $\mathrm{g}$ ) de plantas de gérbera cultivadas em diferentes doses de potássio e colhidas em diferentes semanas após início dos tratamentos (fresh and dry weight of flower stem $(\mathrm{g})$ of gerbera plants grown in different rates of potassium harvested at different weeks after aplication of treatments). Viçosa, UFV, 2010-2011.

\begin{tabular}{|c|c|c|c|c|c|c|c|}
\hline \multirow{3}{*}{$\begin{array}{l}\text { Dose de } \\
\text { potássio } \\
\text { (g/planta/ } \\
\text { ano) }\end{array}$} & \multicolumn{7}{|c|}{ Massa fresca de haste floral (g) } \\
\hline & \multicolumn{7}{|c|}{ Semanas após inicio dos tratamentos } \\
\hline & 12 & 15 & 19 & 23 & 25 & 28 & 31 \\
\hline 0 & $25,6 \mathrm{Aa}$ & $28,6 \mathrm{ABa}$ & $34,1 \mathrm{ABa}$ & $25,6 \mathrm{Aa}$ & $25,3 \mathrm{Ba}$ & $23,5 \mathrm{Aa}$ & $23,4 \mathrm{Ba}$ \\
\hline 2 & $25,6 \mathrm{Aa}$ & $35,6 \mathrm{ABa}$ & $24,7 \mathrm{Ba}$ & $21,0 \mathrm{Aa}$ & $24,5 \mathrm{Ba}$ & $26,6 \mathrm{Aa}$ & $29,9 \mathrm{ABa}$ \\
\hline 4 & $26,3 \mathrm{Aa}$ & $30,0 \mathrm{Ba}$ & $29,5 \mathrm{ABa}$ & $26,7 \mathrm{Aa}$ & $23,5 \mathrm{Ba}$ & $31,0 \mathrm{Aa}$ & $25,6 \mathrm{Ba}$ \\
\hline 6 & $34,2 \mathrm{Aa}$ & $38,5 \mathrm{Aa}$ & $38,9 \mathrm{Aa}$ & $30,7 \mathrm{Aa}$ & $37,3 \mathrm{Aa}$ & $31,5 \mathrm{Aa}$ & $38,4 \mathrm{Aa}$ \\
\hline \multirow[t]{2}{*}{12} & $33,2 \mathrm{Aa}$ & $31,2 \mathrm{ABa}$ & $29,7 \mathrm{ABa}$ & $22,6 \mathrm{Aa}$ & $23,2 \mathrm{Ba}$ & $26,8 \mathrm{Aa}$ & $23,6 \mathrm{Ba}$ \\
\hline & \multicolumn{7}{|c|}{ Massa seca de haste floral (g) } \\
\hline 0 & $4,3 \mathrm{ABab}$ & $3,3 \mathrm{Dab}$ & $5,0 \mathrm{Ba}$ & $3,7 \mathrm{Bab}$ & 4,0Bab & $3,1 \mathrm{Cb}$ & $3,6 \mathrm{Cab}$ \\
\hline 2 & $4,4 \mathrm{Bab}$ & $5,4 \mathrm{Aa}$ & $3,5 \mathrm{Eab}$ & $3,3 \mathrm{Cb}$ & $3,7 \mathrm{Cab}$ & $3,7 \mathrm{Bab}$ & $4,1 \mathrm{Bab}$ \\
\hline 4 & $3,4 \mathrm{Da}$ & $3,8 \mathrm{Ca}$ & $4,2 \mathrm{Da}$ & $3,8 \mathrm{Ba}$ & $2,9 \mathrm{Da}$ & $3,9 \mathrm{ABa}$ & $3,7 \mathrm{Ca}$ \\
\hline 6 & $4,8 \mathrm{Ba}$ & $5,4 \mathrm{Aa}$ & $5,5 \mathrm{Aa}$ & $4,3 \mathrm{Aa}$ & $5,1 \mathrm{Aa}$ & $4,0 \mathrm{Aa}$ & $5,3 \mathrm{Aa}$ \\
\hline 12 & $5,4 \mathrm{Aa}$ & 4,4Bab & 4,5Cab & $3,4 \mathrm{Cb}$ & $3,8 \mathrm{BCab}$ & $3,8 \mathrm{Bab}$ & 3,8Cab \\
\hline
\end{tabular}

Médias seguidas da mesma letra maiúscula na coluna e minúscula na linha não diferem entre si pelo teste de Tukey ao nível de $5 \%$ de probabilidade (means followed by same uppercase letter in column and lowercase letter in line do not differ by Tukey test at 5\% probability).

Tabela 3. Concentração de nitrogênio, fósforo, potássio, magnésio, cálcio e enxofre em folhas de plantas de gérbera em função da semana após inicio dos tratamentos (concentration of nitrogen, phosphorus, potassium, magnesium, calcium and sulfur in the leaves of gerbera plants depending on weeks after onset of treatments). Viçosa, UFV, 2010-2011.

\begin{tabular}{llccccc}
\hline $\begin{array}{l}\text { Semanas após } \\
\text { início dos trata- } \\
\text { mentos }\end{array}$ & $\mathbf{N}$ & $\mathbf{P}$ & $\mathbf{K}$ & $\mathbf{M g}$ & $\mathbf{C a}$ & $\mathbf{S}$ \\
\cline { 2 - 7 } & $2,62 \mathrm{ab}$ & $0,24 \mathrm{ab}$ & $1,77 \mathrm{a}$ & $0,17 \mathrm{~b}$ & $0,75 \mathrm{a}$ & $0,16 \mathrm{bc}$ \\
17 & $1,91 \mathrm{~b}$ & $0,16 \mathrm{~b}$ & $1,54 \mathrm{a}$ & $0,14 \mathrm{~b}$ & $075 \mathrm{a}$ & $0,13 \mathrm{c}$ \\
25 & $2,83 \mathrm{a}$ & $0,26 \mathrm{a}$ & $1,61 \mathrm{a}$ & $0,26 \mathrm{a}$ & $0,93 \mathrm{a}$ & $0,22 \mathrm{a}$ \\
31 & $2,60 \mathrm{ab}$ & $0,29 \mathrm{a}$ & $1,50 \mathrm{a}$ & $0,25 \mathrm{a}$ & $0,89 \mathrm{a}$ & $0,19 \mathrm{ab}$ \\
37 &
\end{tabular}

Médias seguidas pela mesma letra na coluna não diferem entre si pelo teste de Tukey ao nível de $5 \%$ de probabilidade (means followed by same letters in column do not differ by Tukey test at $5 \%$ of probability).

presente experimento, a maior dose utilizada não apresentou a melhor resposta porque pode ter sido em excesso para a planta. Segundo Marschner (1995), o potássio é exportado da folha para o floema, juntamente com a sacarose, tendo grande importância no gradiente osmótico entre a fonte e o dreno. Como a inflorescência é um forte competidor por esse nutriente, o suprimento equilibrado diferente, Guerrero (2009) e Dufault et al. (1990) não constataram melhoria na qualidade de gérbera de vaso e de hastes florais respectivamente, com o aumento da dose de potássio, ate $220 \mathrm{~kg} \mathrm{ha}^{-1}$. Para produção de hastes classificadas como A1 (Figura 2), a maior produção foi observada na ausência de aplicação de potássio. Essa maior produção de hastes do tipo A1 para a ausência de aplicação de K ocorreu em função da menor produção de hastes do tipo extra observada nessa dose.

Para produção total de hastes comerciais (somatório de hastes classificadas como extra e A1), não houve efeito das doses de potássio. A produção total de hastes comerciais foi de $1,74,1,61$, $1,72,1,85$ e 1,83 hastes/planta/mês para $0,2,4,6$ e $12 \mathrm{~g}$ de K/planta/ano, respectivamente.

As concentrações dos nutrientes estavam dentro da faixa recomendada por Valenzuela (2001) para a cultura da gérbera (20-50 $\mathrm{g} \mathrm{kg}^{-1}$ de fósforo, $25-45 \mathrm{~g}$ $\mathrm{kg}^{-1} \mathrm{~K}, 10-35 \mathrm{~g} \mathrm{~kg}^{-1} \mathrm{Mg}, 10-35 \mathrm{~g} \mathrm{~kg}^{-1} \mathrm{Ca}$ e 2,5-5,0 $\mathrm{g} \mathrm{kg}^{-1} \mathrm{~S}$ ). Para o magnésio, cálcio e potássio, as concentrações foram abaixo das recomendadas (Valenzuela, 2001), mas não houve sintomas visuais de deficiência nas plantas e foram semelhantes aos valores encontrados por Dufault et al. (1990). Esses autores constataram concentrações no tecido foliar de gérbera de $0,32,1,6$ e 0,70 $\mathrm{dag} / \mathrm{kg}$ de $\mathrm{Mg}, \mathrm{K}$ e Ca, respectivamente.

Não houve efeito de doses de K na concentração dos macronutrientes na folha de gérbera. Estes resultados, são semelhantes aos observados por Guerrero et al. (2012) que, estudando fontes e doses de potássio em gérbera de vaso, encontraram que não houve influência do cloreto de potássio na concentração dos demais nutrientes. A ausência de interferência de potássio na absorção dos demais nutrientes pode ser devida a não ter sido excessiva para as plantas para causar desequilíbrio nutricional.

Para o nitrogênio, fósforo e enxofre houve influencia da época de coleta, o que pode ser devido às variações de temperatura, umidade e radiação solar que ocorreram durante o período de colheita, que podem ter influenciado na absorção (Tabela 3). Esses resultados diferem dos 


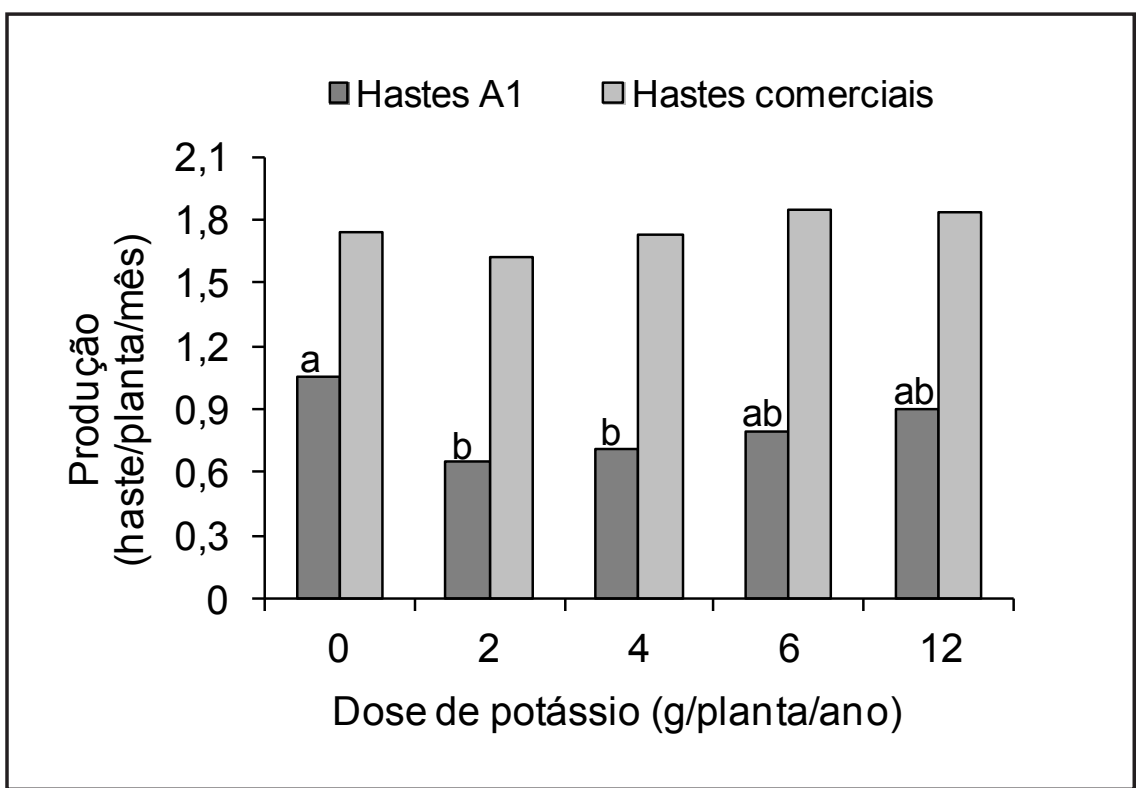

Figura 2. Produção de hastes comerciais e A1 em plantas de gérbera em função de doses de potássio. Colunas seguidas da mesma letra não diferem entre si pelo teste de Tukey ao nível de $5 \%$ de probabilidade (marketable and A1 production of stems of gerbera depending on rates of potassium. Columns followed by the same letter do not differ by Tukey test at $5 \%$ probability). Viçosa, UFV, 2010-2011.

observados por Jeong et al. (2009) que, estudando a concentração de nutrientes em gérbera de vaso em função da idade da planta, observaram aumento da concentração de nutrientes com o aumento da idade com a máxima concentração observada durante o florescimento. Isso não foi observado nesse experimento, uma vez que as plantas já encontravam-se na fase de florescimento, ou seja na fase adulta e com 3 anos após plantio, na época de coleta das folhas. Pode-se concluir que a dose de $6 \mathrm{~g}$ de potássio/ planta/ano proporcionou maior comprimento de hastes e massa fresca e seca de gérbera e as doses estimadas de 7,8 e 7,1 g maior longevidade e produção de hastes extra.

\section{REFERÊNCIAS}

BARBOSA JG; SANTOS JM; GROSSI JAS; CECON PR; RODRIGUES HP; FINGER FL. 2007. Quality and commercial grade of rose yields as affected by potassium applications through drip irrigation. Acta Horticulturae. 751: 83-87.

BARBOSA MA. 2009. Produção de crisântemos de corte sob diferentes relações $\mathrm{N}: \mathrm{K}$ e aplicação de fungicida via solução nutritiva. Viçosa: UFV (Tese doutorado).

DUFAULT RD; PHILLIPS TL; KELLY JW.
1990. Nitrogen and potassium fertility and plant populations influence field production of gerbera. Hortscience 25: 1599-1602.

GREWAL HS; WILLIAMS R. 2002. Influence of potassium fertilization on leaf to stem ratio, nodulation, herbage yield, leaf drop, and common leaf spot disease of alfalfa. Journal of Plant Nutrition 25: 781-795.

GUERRERO AC. 2009. Aplicação de cloreto e silicato de potássio em gérbera (Gerbera jamesonii L.) de vaso. Botucatu: UNESP. (Dissertação mestrado).

GUERRERO AC; FERNANDES DM; LUDWIG F. 2012. Acúmulo de nutrientes em gérbera de vaso em função de fontes e doses de potássio. Horticultura Brasileira 30: 201-208.

JEONG KY; WHIPKER B; McCALL JF. 2009. Gerbera leaf tissue nutrient sufficiency ranges by chronological age. Acta Horticulturae 843: 183-190.

LUDWIG F; FERNANDES DM; MOTA PRD; VILLAS BÔAS RL. 2010. Crescimento e produção de gérbera fertirrigada com solução nutritiva. Horticultura Brasileira 28: 424-429.

MALAVOLTA E. 2006. Manual de nutrição mineral de plantas. São Paulo: Editora Agronômica Ceres. 638p.

MARSCHNER H. 1995. Mineral nutrition of higher plants. 2.ed. San Diego: Academic Press. 902p.

MERCURIO G. 2002. Gerbera cultivation in greenhouse. 1ed. Italy: Schereus. 206p.

MOHARYA AD. 2004. Effect of phosphurus and potash on flower quality and vase life of gerbera grown under polyhouse conditions. Orissa Journal of Horticulture 2: 19-21.

RODRIGUES TM; RODRIGUES CR; PAIVA R; FAQUIN V; PAIVA PDO; PAIVA PV. 2008. Níveis de potássio em fertirrigação interferindo no crescimento/desenvolvimento e qualidade de crisântemo. Ciência. E Agrotecnologia 32: 1168-1175.

SINGH AK. 2006. Flower crops: Cultivation and management. Ed. New India Publishing. 436p.

TAIZ L; ZEIGER E. 2008 Fisiologia Vegetal. Tradutor: Eliane Romanato. Santarém. Artmed. $4^{\mathrm{a}}$ ed. $820 \mathrm{p}$.

VALENZUELA M. 2001. Gerbera. Ediciones Hortitecnia Ltda. 60p. 